\title{
PEOT/PBT Guides Enhance Nerve Regeneration in Long Gap Defects
}

Citation for published version (APA):

Santos, D., Wieringa, P., Moroni, L., Navarro, X., \& Del Valle, J. (2017). PEOT/PBT Guides Enhance Nerve Regeneration in Long Gap Defects. Advanced Healthcare Materials, 6(3), [1600298]. https://doi.org/10.1002/adhm.201600298

Document status and date:

Published: 01/02/2017

DOI:

10.1002/adhm.201600298

Document Version:

Publisher's PDF, also known as Version of record

Document license:

Taverne

Please check the document version of this publication:

- A submitted manuscript is the version of the article upon submission and before peer-review. There can be important differences between the submitted version and the official published version of record.

People interested in the research are advised to contact the author for the final version of the publication, or visit the DOI to the publisher's website.

- The final author version and the galley proof are versions of the publication after peer review.

- The final published version features the final layout of the paper including the volume, issue and page numbers.

Link to publication

\footnotetext{
General rights rights.

- You may freely distribute the URL identifying the publication in the public portal. please follow below link for the End User Agreement:

www.umlib.nl/taverne-license

Take down policy

If you believe that this document breaches copyright please contact us at:

repository@maastrichtuniversity.nl

providing details and we will investigate your claim.
}

Copyright and moral rights for the publications made accessible in the public portal are retained by the authors and/or other copyright owners and it is a condition of accessing publications that users recognise and abide by the legal requirements associated with these

- Users may download and print one copy of any publication from the public portal for the purpose of private study or research.

- You may not further distribute the material or use it for any profit-making activity or commercial gain

If the publication is distributed under the terms of Article $25 \mathrm{fa}$ of the Dutch Copyright Act, indicated by the "Taverne" license above, 


\title{
PEOT/PBT Guides Enhance Nerve Regeneration in Long Gap Defects
}

\author{
Daniel Santos, Paul Wieringa, Lorenzo Moroni, Xavier Navarro, and Jaume Del Valle*
}

Development of new nerve guides is required for replacing autologous nerve grafts for the repair of long gap defects after nerve injury. A nerve guide comprised only of electrospun fibers able to bridge a critical (15 $\mathrm{mm}$ ) nerve gap in a rat animal model is reported for the first time. The nerve conduits are made of poly(ethylene oxide terephthalate) and poly(butylene terephthalate) (PEOT/ PBT), a biocompatible copolymer composed of alternating amorphous, hydrophilic poly(ethylene oxide terephthalate), and crystalline, hydrophobic poly(butylene terephthalate) segments. These guides show suitable mechanical properties, high porosity, and fibers aligned in the longitudinal axis of the guide. In vitro studies show that both neurites and Schwann cells exhibit growth alignment with PA fibers. In vivo studies reveal that, after rat sciatic nerve transection and repair with PEOT/PBT guides, axons grow occupying a larger area compared to silicone tubes. Moreover, after repair of limiting (10 mm) and critical $(15 \mathrm{~mm}$ ) nerve gaps, PEOT/PBT guides significantly increase the percentage of regenerated nerves, the number of regenerated myelinated axons, and improve motor, sensory, and autonomic reinnervation in both gaps. This nerve conduit design combines the properties of PEOT/ PBT with electrospun structure, demonstrating that nerve regeneration through long gaps can be achieved through the design of instructive biomaterial constructs.

functional reinnervation of target organs. However, this requires tension-free direct suturing of lacerated nerves and, therefore, cannot be applied to the nerve defects that result from most transection injuries..$^{3}$ The common clinical practice to bridge a nerve defect is the use of an autologous nerve graft. However, autograft repair presents several disadvantages, such as the use of sensory-only nerves, mismatches in size and fascicular pattern regarding both proximal and distal stumps, donor site morbidity, and possible requirement of a second surgical procedure caused by painful neuroma formation or scarring. ${ }^{[4,5]}$ These drawbacks have driven the development of alternative solutions to repair peripheral nerve discontinuities.

An established alternative to autografts is the entubulation procedure using synthetic nerve conduits to repair nerve lesions, with a variety of conduits that are commercially available for clinical use. ${ }^{[6,7]}$ This technique has some advantages over autografts, such as limiting fibroblast invasion at the repair site, avoiding donor site morbidity, neuroma and scar forma-

\section{Introduction}

After peripheral nerve transection due to injury, a gap between proximal and distal nerve stumps is often created as a result of nerve retraction, tissue loss, or the need to remove neuromas. ${ }^{[1,2]}$ The capacity of the peripheral nervous system to regenerate is well known, with reports showing that reanastomosed nerve ends successfully undergo axon regeneration and

\footnotetext{
Dr. D. Santos, Prof. X. Navarro, Dr. J. Del Valle ${ }^{[+]}$

Institute of Neurosciences

Department of Cell Biology

Physiology and Immunology

Universitat Autònoma de Barcelona, and CIBERNED

08193 Bellaterra, Spain

E-mail: jaume.delvalle@uab.cat

Dr. P. Wieringa, Prof. L. Moroni

Department of Complex Tissue Regeneration

MERLN Institute

Maastricht University

6229 ER, Maastricht, The Netherlands

${ }^{[+]}$Present address: Unitat de Fisiologia Mèdica, Facultat de Medicina, Universitat Autònoma de Barcelona, E-08193 Bellaterra, Spain

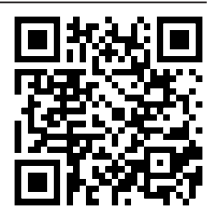

DOI: 10.1002/adhm.201600298 tion, and facilitating the accumulation of neurotrophic factors within the tube lumen. ${ }^{[8]}$ However, despite the success of this approach, these nerve conduits cannot always achieve similar or better outcomes compared to autograft repair.

The main limitation of the entubulation strategy is the length of the gap. Nerve regeneration through hollow tubes made of silicone or other synthetic materials fails if the gap is longer than a limiting size: $4 \mathrm{~mm}$ in the mouse, ${ }^{\left[{ }^{[]}\right.} 10 \mathrm{~mm}$ in the rat, ${ }^{[10,11]}$ and $30 \mathrm{~mm}$ in large primates. ${ }^{[12]}$ Clinically, nerve injury often results in far-reaching gap lengths, leading to the continued development of new nerve guides capable of promoting regeneration over these long, critical distances such as $15 \mathrm{~mm}$ in the rat model.

Several studies have tested nerve conduits of different biomaterials and of different designs in order to enhance nerve regeneration and effectively repair longer nerve defects. ${ }^{[13-15]}$ In particular, continued advances in biofabrication have shown that material selection in combination with a tailored conduit design can improve nerve regeneration through long gaps. This includes modifying the surface structure of the conduit wall to promote cellular adhesion and guidance ${ }^{[16]}$ and incorporating pores within the conduit, optimally ranging from 5 to $30 \mu \mathrm{m}$, to improve nutrients exchange while limiting the invasion of 
inflammatory cells. ${ }^{[7]}$ However, the autograft still outperforms these innovative designs.

To further promote nerve growth over long gaps, the incorporation of growth factors within the scaffold has also been implemented. ${ }^{[8]}$ While this approach has resulted in promising outcomes, the addition of such factors often translates to more complex and costly production and additional regulatory hurdles to be overcome before use in a healthcare setting; ${ }^{[17,18]}$ indeed, none of the approved, commercially available conduits include such factors. ${ }^{[7,19]}$ Therefore, the development of a nerve conduit that stimulates repair on the basis of intrinsic material properties and structural design remains a relevant objective within the healthcare domain.

Toward this aim, the present study introduces for the first time a nerve conduit constructed from poly(ethylene oxide terephthalate) and poly(butylene terephthalate) (PEOT/PBT) copolymer, establishing this material as a promising candidate for the field of peripheral nerve repair. PEOT/PBT, known commercially as polyactive (PA), is a family of biodegradable copolymers comprised of random blocks of amorphous, hydrophilic PEOT segments, and crystalline, hydrophobic PBT segments. Changing the copolymer ratio of PBT to PEOT allows the material properties to be uniquely tuned in order to elicit a desired biological response, meanwhile retaining satisfactory biocompatibility. ${ }^{[20]}$ In addition to having limited adverse effects on the surrounding tissue during implantation, PEOT/ PBT is flexible in terms of processing methods and has been used in various strategies for repairing different tissues such as tympanic membrane replacement,,${ }^{[21]}$ cartilage regeneration, ${ }^{[22]}$ coatings on dental ${ }^{[23]}$ and hip ${ }^{[24]}$ implants, and as bone cement restrictor which has been approved by the US Food and Drug Administration ${ }^{[25]}$ for clinical use in humans.

In the current study, a purposely designed nerve conduit produced by electrospinning is evaluated for both limiting $(10 \mathrm{~mm})$ and critical $(15 \mathrm{~mm})$ nerve gap defects in the rat sciatic nerve. The composition of PEOT/PBT 300 55/45 was employed because it has proven cell adhesive properties and long resorption time ( $>6$ months), suitable for providing long-term support for cell growth. ${ }^{[20]}$ Furthermore, the PA $30055 / 45$ polymer can be readily processed by electrospinning, ${ }^{[21,22]}$ a method of fabricating polymeric fibrous meshes that exhibit topographical guidance for neurite growth and glial cell migration ${ }^{[26]}$ and can produce tissue scaffolds with tailored porosity. ${ }^{[27]}$ The resulting conduit is comprised of an oriented fibrous mesh that incorporates topographical guidance and exhibits pores that are 8-10 $\mu \mathrm{m}$ in diameter.

To our knowledge, there are no studies on the efficacy of electrospun nerve guides that repair both limiting and critical gap lengths without the help of other trophic factors or cells. To explore this, we purposely designed and characterized the reported electrospun PA nerve guides. The effect of these nerve guides on axonal growth was evaluated both in vitro and in vivo, where we compared the performance with a standard silicone tube. Our results indicate that PA nerve guides enhance functional recovery for both gaps length, with the fibrous scaffold design shown to support axonal growth, nonneuronal cell migration, and extracellular matrix formation throughout the luminal volume. The combination of selected material properties with purposely designed fibrous scaffolding represents a novel advance compared with the majority of nerve conduits tested so far, and establishes PEOT/PBT conduit as a promising device to be used in clinics for repair of peripheral nerve injuries.

\section{Results}

\subsection{Characterization of the PA Guides}

Nerve guides were examined under scanning electron microscopy (SEM), confirming an inner diameter of $2 \mathrm{~mm}$ (Figure 1A) and an approximate wall thickness of $75 \mu \mathrm{m}$ (Figure 1B). Closer examination of the nerve guide cross section (Figure 1B) revealed a large porous internal structure (Figure 1C) with an estimated porosity of $62.7 \pm 1.3 \%$. Measured pore diameters on the inner and outer surfaces ranged from 2 to $24 \mu \mathrm{m}$, with respective average values of $8.02 \pm 3.35 \mu \mathrm{m}$ (Figure 1E) and $10.22 \pm 3.8 \mu \mathrm{m}$ (not shown). SEM examination under higher magnification (Figure 1D) revealed that the electrospun nanofibers were consistently well formed and had a smooth morphology (Figure 1E,F) with a range of diameter from 1 to $2 \mu \mathrm{m}$ (average $1.44 \pm 0.29 \mu \mathrm{m}$ ) (Figure 1G). Fibers showed a general orientation of $1.4^{\circ} \pm 0.37^{\circ}$ (Figure $1 \mathrm{H}$ ) from the longitudinal axis of the nerve guide, creating topographical guidance cues for guiding axonal growth. Also observed under SEM were distinct locations where overlapping fibers had slightly fused with one another (Figure 1F). Fiber fusion could be attributed to the retention of small amounts of solvent that allowed fibers to merge when coming in contact during deposition and form physical cross-links after complete evaporation of the solvent. Mechanical testing showed that the nerve guides exhibited highly elastic behavior, with a Young's modulus of $10.5 \pm 2.6 \mathrm{MPa}$, an ultimate strength of $2.7 \pm 0.2 \mathrm{MPa}$, and an elongation at failure of $308 \pm 75 \%$ strain. By comparison, a thin film of PA was found to have a Young's modulus of $75.4 \pm 15.4 \mathrm{MPa}$, an ultimate strength of $14.9 \pm 3.6 \mathrm{MPa}$, and an elongation at failure of $137 \pm 42 \%$ strain (Figure 1I).

\subsection{In Vitro Neurite Growth Results}

Over a $5 \mathrm{~d}$ period, immunostaining with $\beta$ III-tubulin of growing neurites from explanted dorsal root ganglia (DRG) maintained on PA nerve guides showed directed neurite outgrowth (Figure 2B), whereas staining for the S100 marker revealed Schwann cell oriented migration (Figure 2D). Figure 2C shows the calculated neurite growth distribution around the explanted DRG, with the average neurite distribution of three samples shown in Figure 2F. The mean neurite distance was $290 \pm 38 \mu \mathrm{m}$. The neurite length on laminin-coated glass surface (Figure 2A) was not significantly different from the nerve guide substrate, with a mean neurite length of $487 \pm 219 \mu \mathrm{m}$ $(p=0.26$; Figure 2E).

Further examination showed that the general direction of neurite growth on PA differs from the underlying fiber orientation by an average of only $2.67^{\circ} \pm 3.61^{\circ}$. In contrast, no discernible orientation was observed for neurite growth on glass substrate. To quantify the overall pattern of neurite extension, 

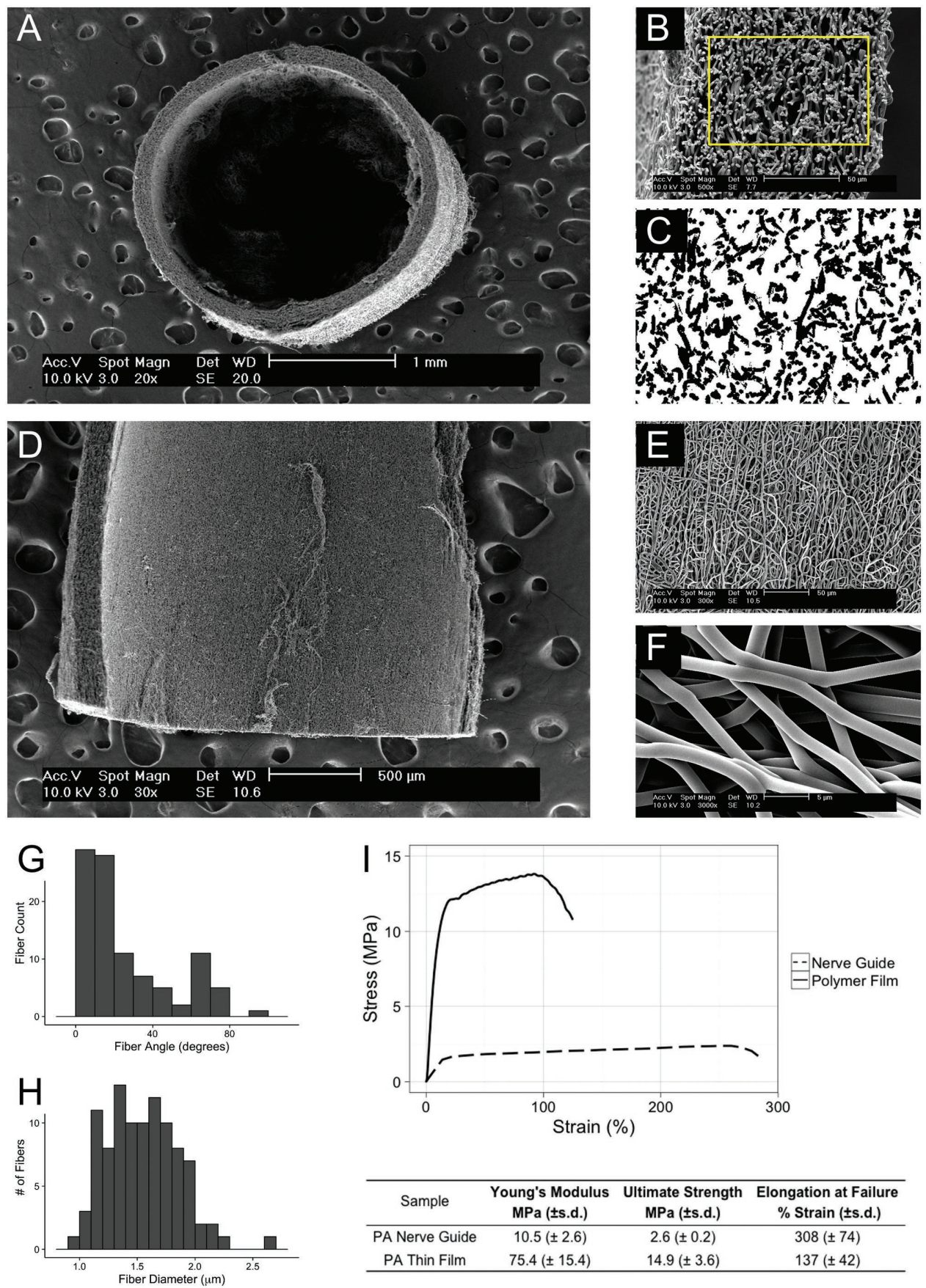

\begin{tabular}{cccc}
\hline Sample & $\begin{array}{c}\text { Young's Modulus } \\
\mathrm{MPa}( \pm \text { s.d. })\end{array}$ & $\begin{array}{c}\text { Ultimate Strength } \\
\mathrm{MPa}( \pm \text { s.d.) }\end{array}$ & $\begin{array}{c}\text { Elongation at Failure } \\
\% \text { Strain }( \pm \text { s.d. })\end{array}$ \\
\hline PA Nerve Guide & $10.5( \pm 2.6)$ & $2.6( \pm 0.2)$ & $308( \pm 74)$ \\
PA Thin Film & $75.4( \pm 15.4)$ & $14.9( \pm 3.6)$ & $137( \pm 42)$ \\
\hline
\end{tabular}

Figure 1. A) Scanning electron images of nerve guide cross section and B) a high magnification image of a cross section of the nerve guide side wall. C) Wall cross section images were thresholded to estimate nerve guide porosity. D) SEM analysis of the nerve guide interior revealed E) well-formed fibers with a general orientation in the direction of the longitudinal axis. F) Closer inspection also revealed that fibers were merged at specific locations. $\mathrm{G})$ Plots of distribution of fiber diameters and $\mathrm{H}$ ) distribution of fiber orientation and I) a typical stress/strain relationship for PA nerve guides and PA films. A strain rate of $100 \% \mathrm{~min}^{-1}$ was applied to samples and the resulting stress was recorded to evaluate the Young's modulus, ultimate tensile strength at failure and the maximum strain at failure.

the relative dispersion of neurite extension from a radial axis was calculated to produce a value between 0 and 1 ; a value of 1 indicates growth that has maximal deviation $\left(90^{\circ}\right)$ from the chosen axis, while growth which overlaps with the axis results in a 0 value. The longitudinal axis of the nerve guide was used to calculate an average dispersion of $0.173 \pm 0.034$, indicating highly oriented growth (Figure 2B,F). By comparison, neurite growth on glass substrate (Figure 2A,E) exhibited an average dispersion of $0.594 \pm 0.05$, indicating no directionality. Schwann cell migration was found to be also oriented in the direction of PA fiber alignment, with a dispersion of $0.266 \pm 0.199$, a mean migration distance of $80.86 \pm 32.8 \mu \mathrm{m}$, and a maximum 

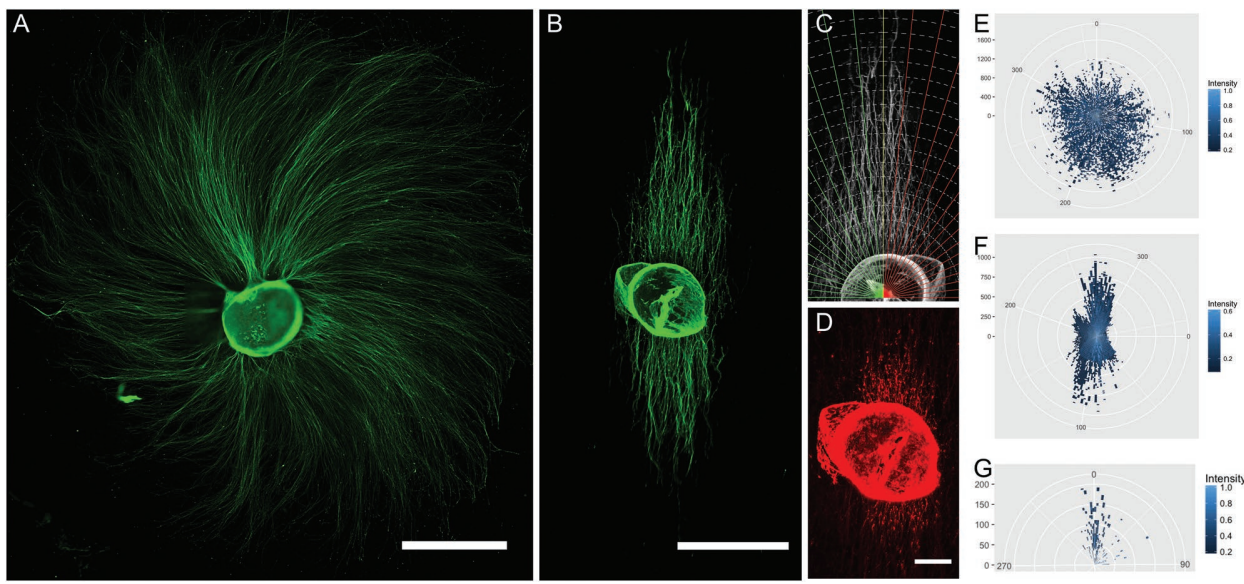

Figure 2. Outgrowth of an explanted DRG A) on a flat glass substrate and B) on the inside surface of a PA nerve guide. Neurite growth was evaluated by applying spatial bins in a radial fashion from the center of the DRG, as shown in (C). D) The nerve guide also supports Schwann cell migration. The angular frequency of the bins was $2^{\circ}$ with a fixed bin area of $50 \mu \mathrm{m}^{2}$. Images of DRG outgrowth were evaluated as described and the resulting values were averaged over each group $(n=3)$ to provide mean growth for both E) flat glass substrates and F) nerve guide substrates. $\mathrm{G})$ Similar analysis shows directed Schwann cell migration.

migration distance of $743.0 \pm 513.7 \mu \mathrm{m}$. (Figure $2 \mathrm{G}$ ). These findings were further supported by in vitro cultures of sensory neurons and Schwann cell lines on oriented PA fibers compared to flat films of PA and silicone (Supporting Information). Both cell types exhibited an elongated morphology with clear alignment in the direction of fiber orientation. Comparatively, no evidence of cellular guidance was observed for cells grown on PA film, silicone or glass substrates.

\subsection{Morphological Results of Short-Term Regenerated Nerves}

The first in vivo studies were conducted on $6 \mathrm{~mm}$ nerve defects, as it has been reported that all nerves regenerate through a silicone guide in such relatively short gap. ${ }^{[10,28]}$ This was performed to establish that PA guides produced similar or better outcomes in terms of nerve regeneration compared to silicone tubulation, before investigating the more challenging conditions of critical nerve gaps. Two weeks after repairing a $6 \mathrm{~mm}$ sciatic nerve gap with silicone or PA tubes, a regenerating cable was found in all the rats. Surprisingly, in contrast to the classical thin nerve cable formed in the center of the standard silicone tubes (Figure 3A), ${ }^{[1]}$ a distinct regenerated nerve was observed in the PA guides occupying all the internal lumen of the tube (Figure $3 \mathrm{~B}$ ).

Immunohistochemical labeling showed that as early as two weeks after repair a high number of dot-shaped and densely packed axons were present in the silicone tubes (Figure 3A) whereas axons in PA tubes appeared more dispersed (Figure 3B). Similarly, four weeks after repair, nerves regenerated inside silicone tubes showed an organized structure with an outer layer of cells and small axons with a dotted shape in the core of the nerve cable (Figure 3C), whereas axons in PA guides were spread over the whole lumen of the conduit (Figure 3D). Regenerated axons were ensheathed by Schwann cells without difference in both groups, indicating similar progression of axonal regeneration and remyelination (Figure 3E,F). Measurement of the transverse area of the regenerated cable at 2 and 4 weeks indicated that PA guides supported a larger regenerating area compared to silicone tubes (Figure 3G,H).

\subsection{Target Reinnervation and Functional Recovery in Long-Term Regeneration Studies}

Nerve conduction tests performed 1 week after sciatic nerve injury demonstrated complete denervation of the hind limb muscles. At 60 days postoperation (dpo) all PA10 rats showed evidence of reinnervation with recordable compound muscle action potentials (CMAP) in tibialis anterior (TA) and gastrocnemius medialis (GM) muscles whereas only $37.5 \%$ of S10 rats showed positive values. In cases with $15 \mathrm{~mm}$ gap defect, CMAPs in TA and GM muscles were recorded in half of the PA15 rats but in none of S15 rats. At 90 dpo, the differences in CMAPs amplitude between the PA10 and S10 groups increased and still no signs of regeneration for the S15 rats appeared. At the end of the follow up (120 dpo) the mean CMAP amplitude of the TA $(15.2 \pm 2.4 \mathrm{mV})$ and the GM $(17.7 \pm 4.1 \mathrm{mV})$ muscles in the PA10 group were significantly higher than in the S10 group (6.4 $\pm 4.4 \mathrm{mV}$ and 7.6 $\pm 5.1 \mathrm{mV}$, respectively) (Figure 4A,C), while no statistical difference was found for the plantar interossei (PL) muscle (Figure 4E). On the other hand, the PA15 group had significantly higher CMAPs amplitude in the three tested muscles (Figure 4B,D,F) $(6.1 \pm 2.2 \mathrm{mV}$ for TA, $6.0 \pm 2.6 \mathrm{mV}$ for $\mathrm{GM}$, and $0.14 \pm 0.10 \mathrm{mV}$ for PL muscles) compared to the $\mathrm{S} 15$ group $(1.2 \pm 1.2 \mathrm{mV}, 0.7 \pm 0.7 \mathrm{mV}$, and $0 \mathrm{mV}$, respectively; $p<0.05)$.

Regarding sensory function recovery to mechanical stimuli, at 7 dpo no animals showed response in the denervated paw. Comparison between S10 and PA10 (Figure 4G) revealed that at 120 dpo PA10 rats withdrew their hindpaws at lower stimulus intensities in comparison with the S10 rats, thus indicating a lower threshold of sensory stimulation. With regard to $15 \mathrm{~mm}$ gap groups (Figure $4 \mathrm{H}$ ), in the $\mathrm{S} 15$ group none of the rats showed response to mechanical stimuli while PA15 rats showed sensory recovery at 90 and 120 dpo with lower threshold of withdrawal to mechanical stimulation. 

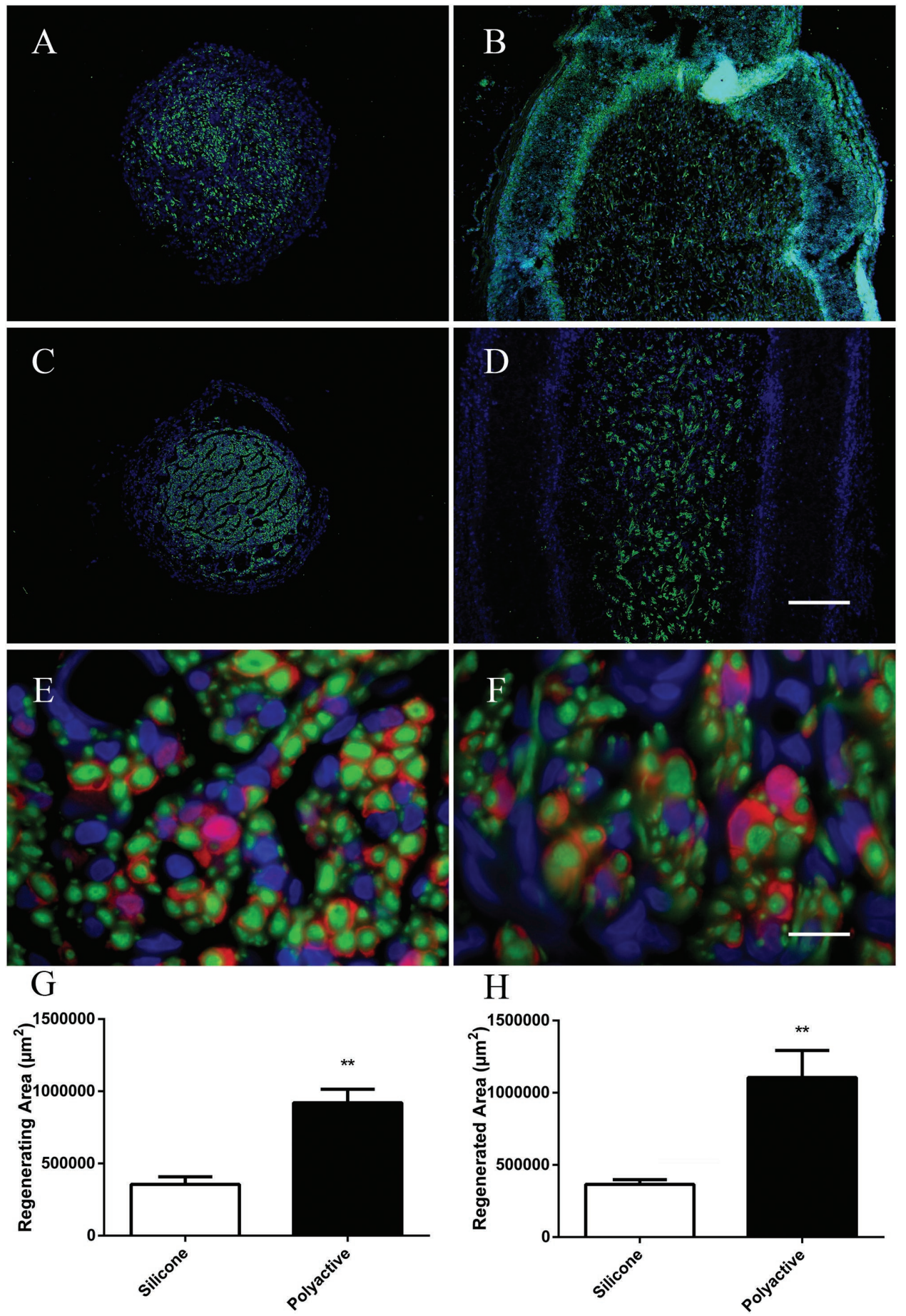

Figure 3. Representative cross section images of the regenerated nerve taken $3 \mathrm{~mm}$ distal to the proximal stump of nerves regenerated through a $6 \mathrm{~mm}$ gap in $A, C$ ) silicone or B,D) PA guides $2(A, B)$ and $4(C, D)$ weeks after repair. Axons are stained with $\beta$ III-tubulin (green) and nuclei with DAPI (blue). E,F) Close view of C (G) and D (F) with Schwann cells stained with $S 100$ (red). G,H) Area of the regenerated nerve at the mid tube (3 mm from the proximal stump) in silicone and PA groups after $2(\mathrm{G})$ and $4(\mathrm{H})$ weeks of regeneration. Data presented as mean \pm SEM, *k $p<0.01$ versus silicone group. Scale bar A-D) $200 \mu \mathrm{m}$ and E-F) $10 \mu \mathrm{m}$.

\subsection{Histological Results}

Macroscopic evaluation of the regenerated nerves at 4 months after injury and repair with silicone (Figure 5A) or PA (Figure $5 \mathrm{C}$ ) guides demonstrated that three of eight animals
(37.5\%) in group S10 presented a regenerative cable at the center of the tube (Figure 5B), whereas only one regenerated nerve (16.6\%) was found in group S15 (Figure 5E). The PA tubes were partially degraded at this time but still opaque (Figure 5D), so macroscopic visualization of the regenerated 


\section{MOTOR FUNCTIONAL RECOVERY}
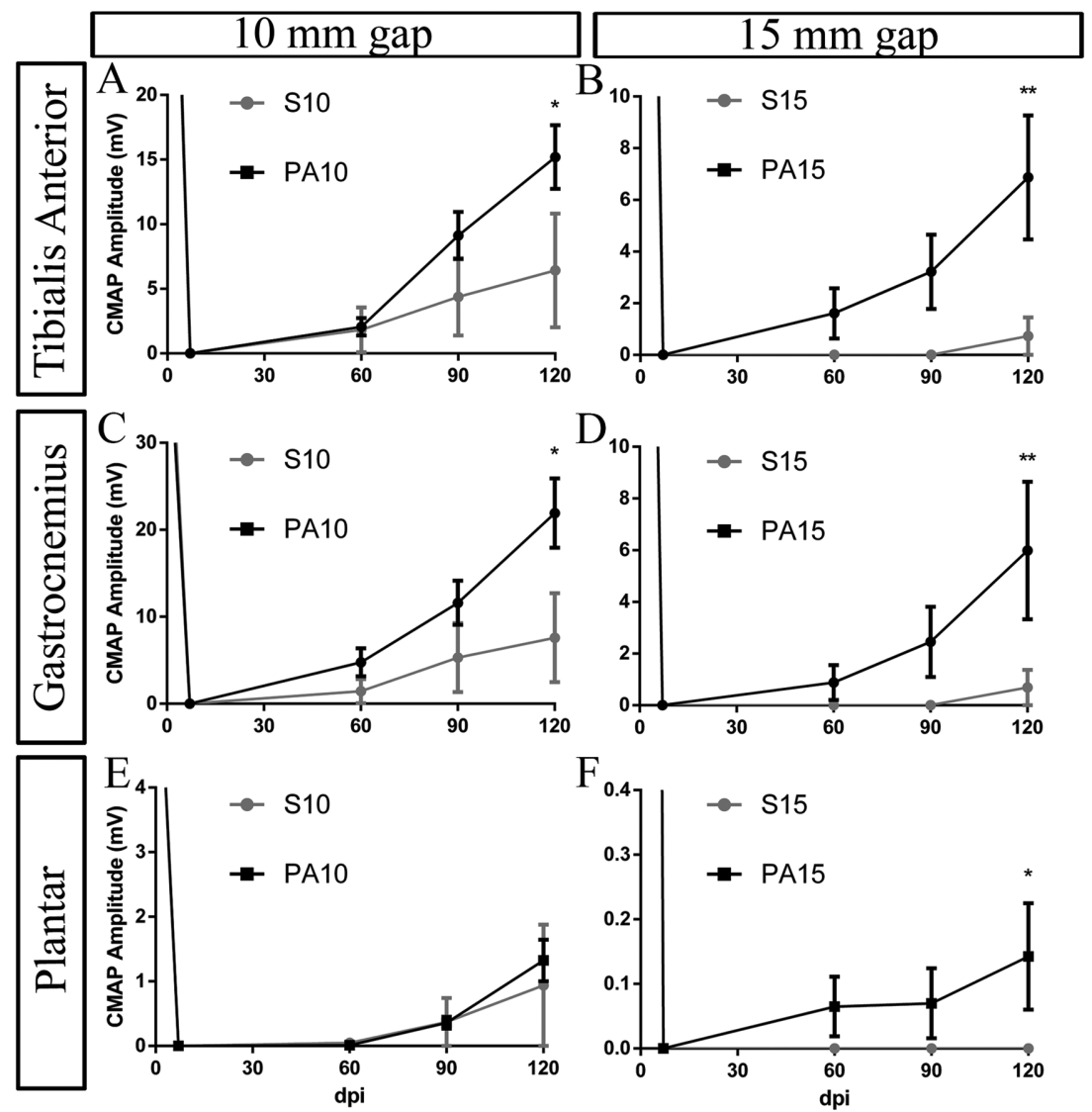

$\mathrm{F}_{0.4}$

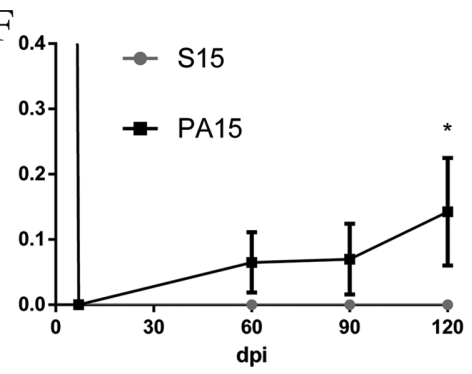

SENSORY FUNCTIONAL RECOVERY
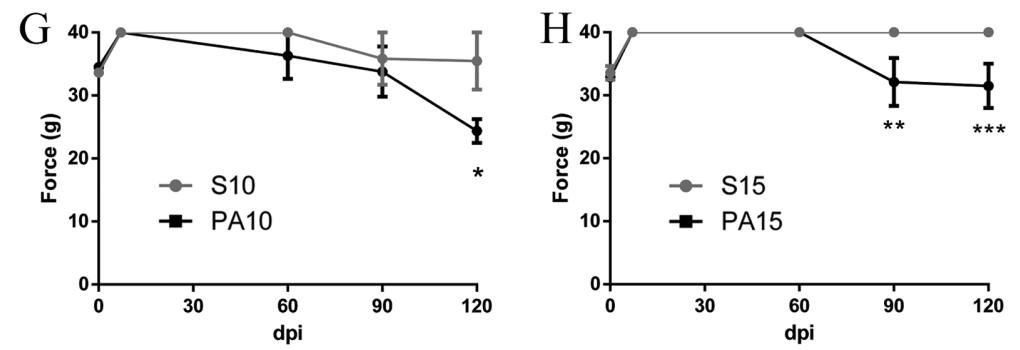

Figure 4. Mean amplitude of the compound muscle action potential (CMAP) of $A, B$ ) tibialis anterior, $C, D)$ gastrocnemius, and $E, F)$ plantar interossei muscles in rats with $A, C, E) 10 \mathrm{~mm}$ and $\mathrm{B}, \mathrm{D}, \mathrm{F}) 15 \mathrm{~mm}$ gap defect during 4 months after sciatic nerve lesion and repair with silicone or PA tubes. Sensory thresholds measured with algesimetry tests (Von Frey test) in rats with G) $10 \mathrm{~mm}$ and H) $15 \mathrm{~mm}$ gap during 4 months after nerve lesion and repair with silicone or PA tubes. Data presented as mean \pm SEM. $* p<0.05,{ }^{* *} p<0.01$ versus S10 and S15 groups. fibers than in S10 nerves (Figure 6C). On the other hand, PA tubes showed a thick wall and the inner area of regeneration occupied by axons, extracellular matrix, and nonneuronal cells (Figure 6B,D,F). Axons could be seen in direct contact with the inner surface of the PA tubes (Figure 6G,H) indicating that the PA conduits also provide a guiding longitudinal structure to the regenerating axons. Morphometric analysis demonstrated that the mean value of endoneurial area (Figure 6I), axon density (Figure 6J), and number of myelinated axons (Figure 6K) at the midpoint of the tubes were significantly higher in both PA groups in comparison with silicone tube groups. Morphometric measurements showed similar axon diameter and myelin thickness for PA and silicone in 10 and $15 \mathrm{~mm}$ groups when taking only into account the regenerated nerves (Figure 6L).

\subsection{Cutaneous Reinnervation of Plantar Skin}

Reinnervation of the target sensory territory of the sciatic nerve, assessed by protein gene product (PGP) immunostaining, showed bundles of fibers forming a subepidermal nerve plexus (SNP) from which single fibers entered the epidermis (Figure 7A-C), and a central plexus innervating the sweat glands (SGs) (Figure 7D-F) in plantar pads of intact and regenerated animals. In rats with a $10 \mathrm{~mm}$ gap lesion there was reduced innervation of the dermis, epidermis, and the SGs in comparison with intact rats. In animals with a $15 \mathrm{~mm}$ gap defect, no evidence of reinnervation was found in S15 rats (Figure 7B,E), whereas PA15 rats showed some nerve bundles in the SNP with spare reinnervation of the epidermis (Figure 7C) and the SGs (Figure 7F).

Quantitative analysis indicated that the number of intraepidermal nerve fibers (IENF) and the number of innervated SGs were higher in the PA10 group than in the S10 group (Figure 7G,H), although not significantly due to the large variability. The PA15 group showed significantly higher reintissue was not possible. All the tubes showed a thick structure filling the lumen. Histological evaluation at the midpoint of the PA tubes indicated that all the animals presented a regenerated nerve in group PA10 (100\%) and five of nine animals in group PA15 (55.5\%) (Figure 5E).

Nerves that regenerated in S10 rats showed a centered cable containing numerous small blood vessels and regenerative units with myelinated axons (Figure 6A), whereas the only regenerated nerve in S15 rats (Figure 6E) had fewer myelinated nervation of epidermis and SGs compared with the S15 group that was completely denervated, further corroborating the results of the sensory functional tests.

\section{Discussion}

After peripheral nerve injury, coaptation of nerve stumps to promote axonal regeneration is not always possible because 

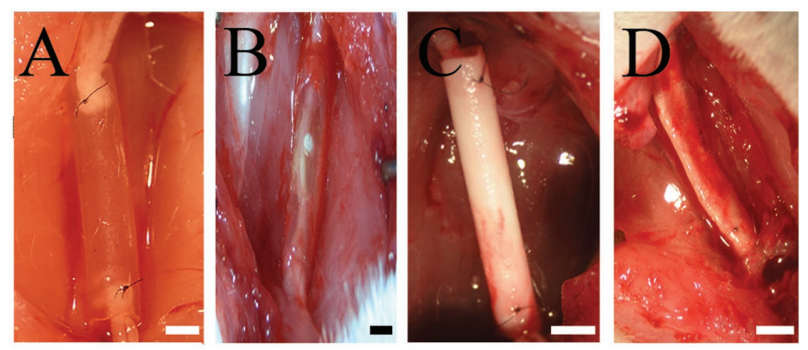

$\mathrm{E}$

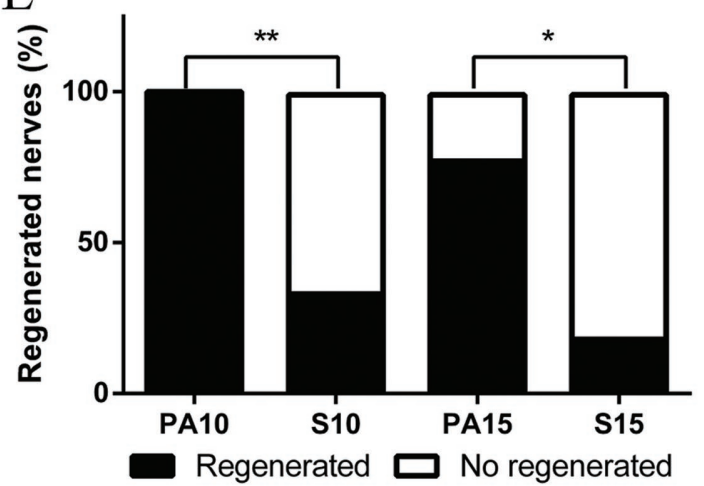

Figure 5. Representative images of $A, C)$ silicone and $B, D) P A$ tubes before (A, B) and after (C, D) $120 \mathrm{~d}$ of regeneration. E) Plots comparing success of nerve regeneration in all groups. $* p<0.05,{ }^{* *} p<0.01$. Scale bar $2 \mathrm{~mm}$.

of nerve retraction or tissue loss. Tube repair is an accepted approach to solve this issue; however, more efforts are needed to improve regeneration through nerve conduits in order to match the performance of autografts. Since the first attempts with tube repair, ${ }^{[2]]}$ different strategies have been tested to enhance regeneration in long gaps including the use of different materials in tube manufacturing, ${ }^{[13]}$ addition of extracellular matrix filling the tube ${ }^{[30]}$ or application of neurotrophic factors. ${ }^{[31]}$

Materials such as polyglycolic acid, poly(lactide-caprolactone), or collagen I have been used to manufacture Food and Drug Administration (FDA) or European (CE) approved commercial neural scaffolds for peripheral nerve repair. ${ }^{[19]}$ Other materials such as chitosan or silk hold great promise ${ }^{[8,32]}$ as they show excellent biocompatibility, biodegradability, and mechanical strength. ${ }^{[33]}$ Indeed, a controlled release of growth factors with silk or chitosan microparticles, ${ }^{[34]}$ functionalization of the scaffold with growth factors, ${ }^{[35]}$ and different fabrication techniques such as electrospinning ${ }^{[36,37]}$ or chemical surface modifications ${ }^{[38]}$ have been able to successfully bridge $10 \mathrm{~mm}$ limiting rat sciatic nerve gaps with similar outcomes to autograft repair. However, peripheral nerve injuries with longer critical nerve gaps often result in poor functional recovery ${ }^{[39]}$ and there is still the need to favorably bridge such nerve defects. From the different fabrication techniques, fibrous nerve conduits produced via electrospinning represent an auspicious biofabrication approach to achieve this aim, with initial studies reporting moderate success. ${ }^{[40,41]}$ One of the major benefits of this technique is the flexibility over the design and composition that can be obtained. Electrospun nerve guides have been created from synthetic polymers, ${ }^{[40,42]}$ natural proteins, ${ }^{[35]}$ or a synthetic/natural blend, ${ }^{[41]}$ which allows tuning of surface chemistry, bioactivity, and degradation properties. Electrospun fibers can also incorporate neurotrophic factors, either via controlled release $e^{[37,42,43]}$ or conjugated to the fiber surface. ${ }^{[35]}$ Nerve guides incorporating Schwann cells represent another strategy employed to enhance axonal growth, ${ }^{[44]}$ and since the first studies reporting the integration of living cells in the electrospinning process ${ }^{[45]}$ this technique has been widely used for the fabrication of a wide range of living scaffolds. ${ }^{[46,47]}$

Nevertheless, current regulations restrict the immediate clinical application of incorporated biological components, ${ }^{[44]}$ which has motivated the development of nerve guides that intrinsically improve nerve growth through optimal material selection and construct design. To this end, fibrous nerve guides have been created with pores ranging from 5 to $30 \mu \mathrm{m}$ in diameter ${ }^{[40,48]}$; this is considered optimal for the influx of nutrients while providing a sufficient barrier to minimize the invasion of inflammatory cells. ${ }^{[7]}$ Electrospun constructs with oriented fibers have also been shown to enhance in vitro neurite elongation and Schwann cells migration. ${ }^{[49]}$ Similarly, aligned fibers have been incorporated within nerve guides ${ }^{[37,50]}$ and have been shown to promote nerve regeneration in vivo. ${ }^{[42,51,52]}$ However, alignment and the subsequent packing density of the oriented fibers can also reduce the pore size below the recommended diameter. ${ }^{[48]}$ Evidence also suggests that smaller nanofibers exhibit higher packing densities that restrict cell infiltration, limiting Schwann cell migration, and neurite extension; fibers $1.5 \mu \mathrm{m}$ in diameter are reported to provide optimal guidance of sensory neurons. ${ }^{[53]}$

In the present study, we characterized a novel nerve guide fabricated from PA through an optimized electrospinning process that realizes an ideal combination of fiber size, fiber alignment, and porosity. To the best of our knowledge, this is the first study to report electrospun nerve guides alone capable of achieving functional repair of a critical nerve gap greater than $10 \mathrm{~mm}$ in the rat sciatic nerve. PA belongs to a family of biocompatible materials which have been used to realize a variety of implantable biomedical devices approved by the FDA. ${ }^{[25]}$ The polymer used in this study (PEOT/PBT 300 55/45) was selected because it promotes cell adhesion and can be readily processed by electrospinning. SEM analysis of the resulting nerve guides revealed well-formed fibers with an average diameter of $1.44 \mu \mathrm{m}$ and a generally aligned, longitudinal orientation. Our in vitro studies confirmed that both neurites and Schwann cells adhered on the surface of the PA fibers and exhibited an aligned growth compared to nonpatterned substrates. This highly oriented neurite extension was achieved without the aid of loading electrospun fibers with trophic factors, as reported by other studies. ${ }^{[37]}$

Because the accessibility of diffusible nutrients is known to be important for improving nerve regeneration, ${ }^{[7]}$ electrospinning was selected as the material processing method; electrospun fibrous meshes of the PEOT/PBT family were previously shown to have significantly improved nutrient diffusion compared to solid film. ${ }^{[54]}$ SEM analysis confirmed that the nerve guides produced in this study were highly porous, with an estimated void space, or volume porosity, of $62 \%$ and an average pore diameter between 8 and $10 \mu \mathrm{m}$, within the recommended range..$^{[7]}$ 


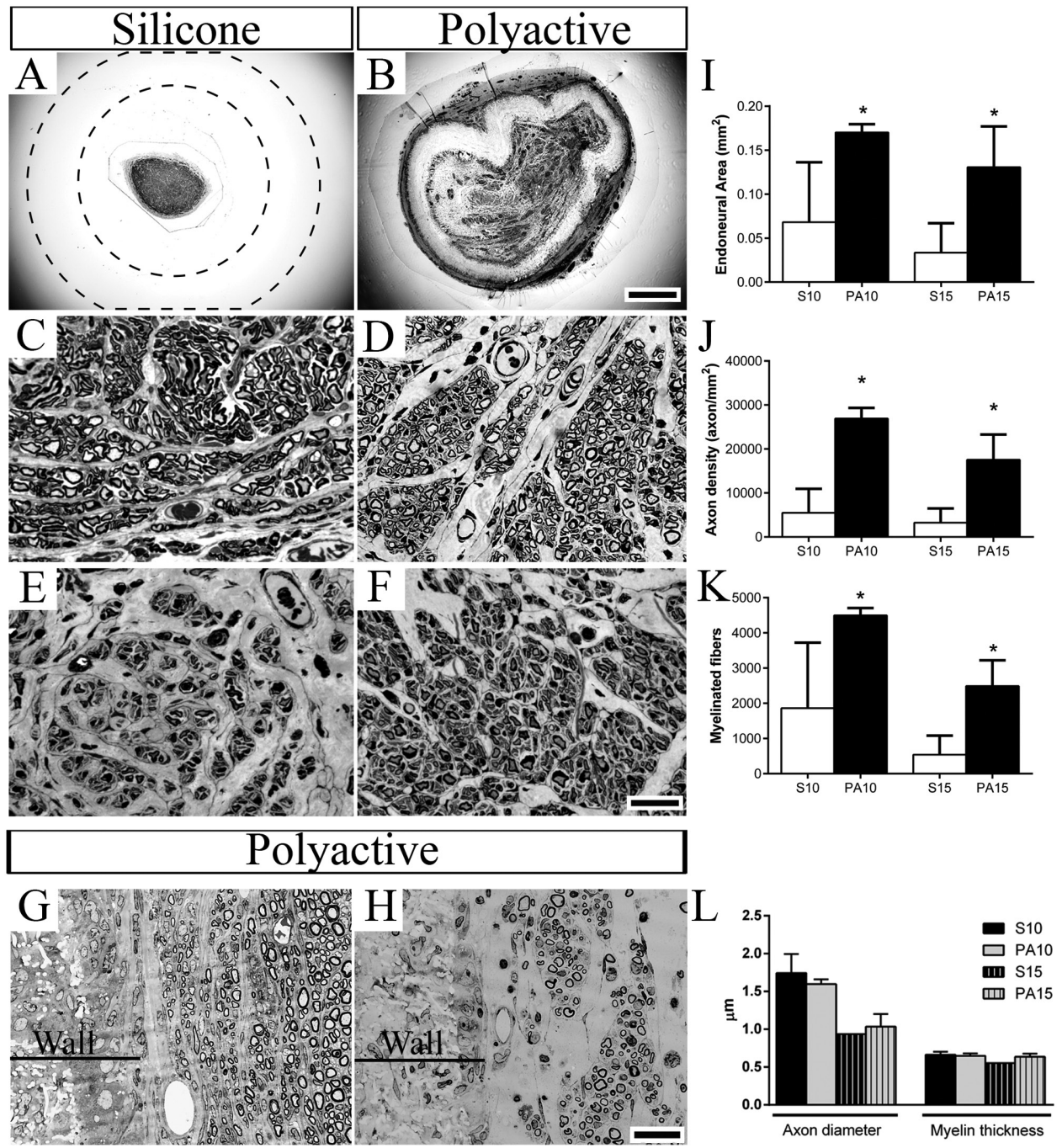

Figure 6. Representative semithin transverse sections of A) S10 and B) PA15 regenerated nerves, the contour of the silicone tube is drawn as a dotted line in panel (A). C-F) Representative images at higher magnification of transverse sections of C) S10, D) PA10, E) S15, and F) PA15 groups $120 \mathrm{~d}$ after repair. G,H) Representative images of myelinated axons growing close to the wall in G) PA10 and H) PA15 rats. I-L) Plots with I) endoneurial area, J) axon density, K) number of regenerated myelinated fibers, and L) morphometric analysis at the mid-tube in groups with 10 and 15 mm gap repaired with silicone or PA tubes. All images were taken 5 and $7.5 \mathrm{~mm}$ distal to proximal stump for the 10 and $15 \mathrm{~mm}$ gap groups, respectively. Data presented as mean \pm SEM. $* p<0.05$ versus S10 and S15 groups; ${ }^{* *} p<0.01$ versus S10 group. Scale bar $500 \mu \mathrm{m}(\mathrm{A}, \mathrm{B}), 25 \mu \mathrm{m}(\mathrm{C}-\mathrm{F})$ and $50 \mu \mathrm{m}(\mathrm{G}-\mathrm{H})$.

While having a high degree of porosity, the nerve conduits were also found to have favorable mechanical properties within the range previously reported ${ }^{[41]}$ with a Young's modulus of around $10 \mathrm{MPa}$ and a maximum strain of $\approx 300 \%$. These findings also indicate that this electrospun PA construct is far more flexible and resilient compared to a solid PA structure. Closer inspection revealed that microfibers slightly fused with one another during the fabrication process, where such physical cross-links are known to improve mechanical properties of electrospun constructs. ${ }^{[55]}$ The nerve guides also maintained an open lumen and did not collapse after $120 \mathrm{~d}$ of supporting nerve regeneration despite having compliant walls with an approximate thickness of $75 \mu \mathrm{m}$ and a high degree of porosity. Moreover, this resilient tubular construct easily accommodated suturing as well as retained the sutures along the four months in vivo experimental time.
Other reports have shown that highly porous nerve guides can be degraded too rapidly to be effective for supporting regeneration of long nerve defects. ${ }^{[56]}$ Polymer degradation often occurs via surface-mediated bulk fragmentation and, therefore, the greater surface area of a porous nerve guide can result in proportionally faster degradation compared to a solid nerve guide of the same material. However, the PA nerve guides in this study were observed to be mostly intact when explanted after four months of implantation; this is in line with previous reports on the degradation of this polymer, which also showed that degradation products are not cytotoxic. ${ }^{[20,57]}$ The relatively slow rate of PA absorption allows these electrospun nerve guides to be highly porous while remaining physically intact, leading to a balance between nutrient influx and sustained directed growth for improved nerve regeneration. 


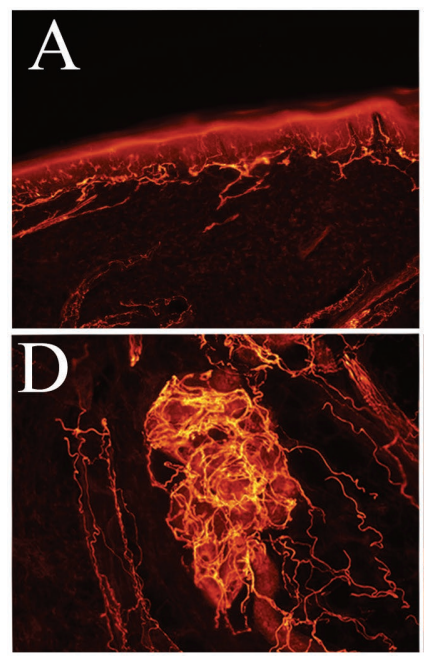

G

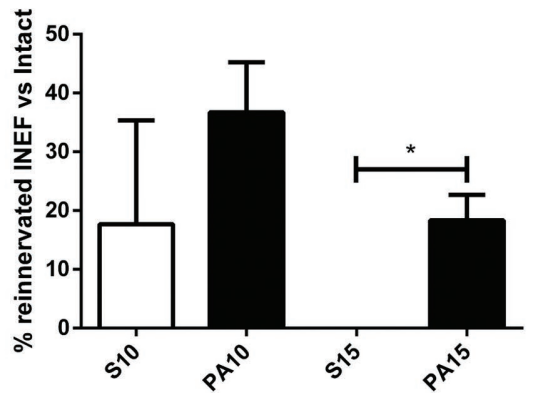

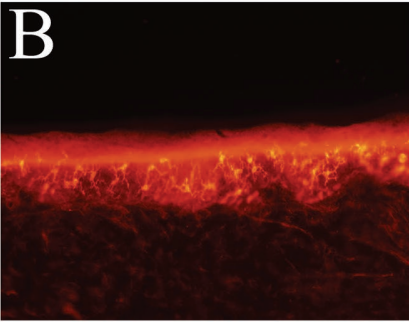
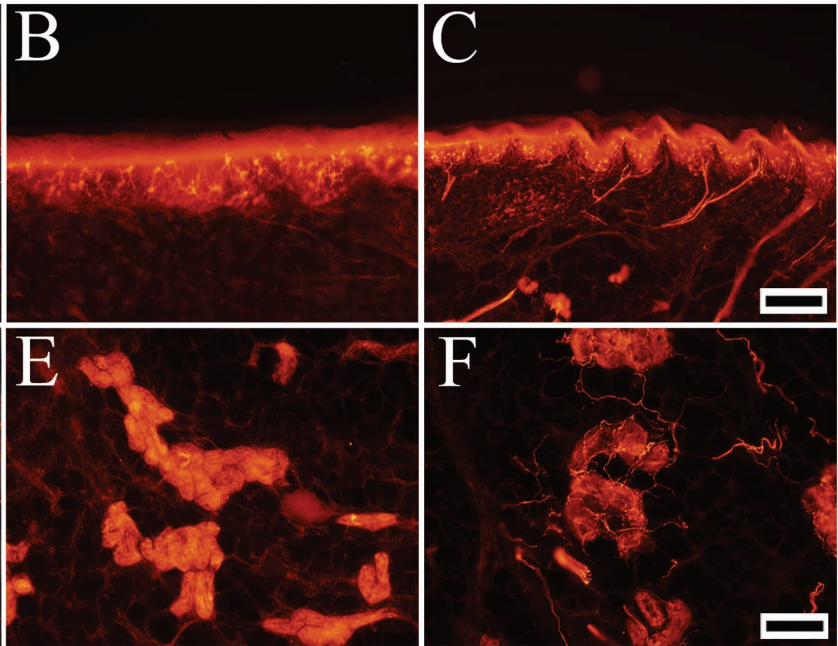

$\mathrm{H}$

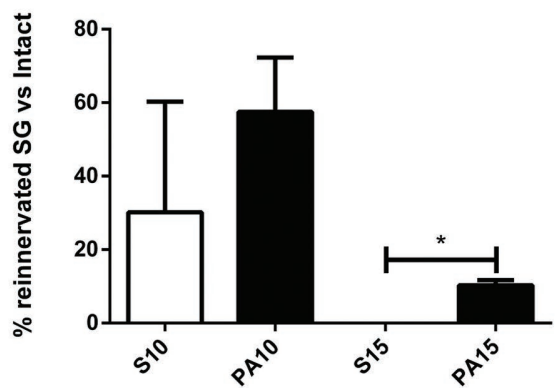

Figure 7. Representative images of footpads immunolabeled for PGP showing the innervation $A-C$ ) of epidermis and D-F) of sweat glands of $A, D)$ intact, B,E) S15, and C,F) PA15 samples. G) Percentage of reinnervated IENF with respect to control values. H) Percentage of reinnervated SGs with respect to control values. Data presented as mean \pm SEM. $* p<0.05$ versus S15 group. Scale bar $100 \mu \mathrm{m}$.

Although the nerve guides remained relatively intact at four months after implantation, we observed that fibers began to progressively invade the lumen of the guide and appeared to provide an unexpected benefit to the regenerative process. This is attributable to the erosion of physical cross-links between fibers, allowing fibers to serve as additional extracellular matrix-like guidance structure for Schwann cell migration and neurite extension. The benefits of explicitly including an intraluminal structure to improve neural regeneration have been widely explored, with a number of strategies incorporating fibrous elements to improve growth. ${ }^{[43,58,59]}$ However, these strategies often need increased manufacturing complexity ${ }^{[16]}$ and intralumen structures can also obstruct regenerative growth, reducing effectiveness. ${ }^{[58,60]}$ In the current study, the appearance of an internal structure is an intrinsic property of the PA nerve guide and is limited to the periphery of the lumen, where it provides additional support for cell adhesion while not obstructing growth through the guide. Furthermore, this partial degradation over time also suggests that this nerve guide becomes progressively more accommodating to maturing neural tissue, thus circumventing the risk of compression of the regenerated nerve that has been observed within traditional solid nerve guides. ${ }^{[16,61]}$

With regard to characterization of the regenerative process, across a short $6 \mathrm{~mm}$ gap at two or four weeks, axons were present in both tubes, but, in contrast to the usual regenerated nerve centered in the silicone tube, the PA guides showed axons spread throughout the internal lumen and also in contact with the wall. This is a novel observation regarding tube repair of nerve defects. We can hypothesize that the permeability of the PA wall and the longitudinal cues offered by PA fibers account for the larger regenerative scaffold inside the PA guide. The formation of a connective cable that connects both nerve stumps over which fibroblasts and Schwann cells migrate to form a new nerve structure that provides support for axonal elongation, are the first steps in the regeneration process in nerve conduits. ${ }^{[1]}$ Axonal regeneration fails to occur in long gaps, over a critical length, because the regenerative capabilities of the nerve stumps are exceeded and the initial cable is not formed. In this situation, the inflow through the porous tube wall of extraneural diffusible factors or of repairing cells may represent an additional support. ${ }^{[62,63]}$ The nerve growth observed in contact with the PA wall indicates that PA guides may serve not only as a tube concentrating the regenerative microenvironment but also as a bridge enhancing the first step of nerve regeneration and facilitating cell migration along and within the tube.

Concerning the more challenging 10 and $15 \mathrm{~mm}$ nerve gaps in the rat sciatic nerve, a separation of $10 \mathrm{~mm}$ has been reviewed to account for about $50 \%$ of regeneration success with silicone and other plastic tubes, whereas a $15 \mathrm{~mm}$ gap is considered critical since no regeneration occurs in those 
Table 1. Summary of data obtained in the present study and previous data autograft after $15 \mathrm{~mm}$ repair from our laboratory after $120 \mathrm{dpi}$.

\begin{tabular}{|c|c|c|c|c|c|c|c|}
\hline Type of repair & $\begin{array}{c}\% \text { of regenerated } \\
\text { animals }\end{array}$ & $\begin{array}{l}\text { \% recovery } \\
\text { of TA CMAP }\end{array}$ & $\begin{array}{l}\% \text { recovery } \\
\text { of PL CMAP }\end{array}$ & $\begin{array}{l}\% \text { recovery in Von } \\
\text { Frey test }^{\mathrm{b})}\end{array}$ & $\begin{array}{l}\text { Myelinated } \\
\text { fibers }\end{array}$ & $\begin{array}{c}\text { Axon } \\
\text { diameter }\end{array}$ & G-ratio \\
\hline Autograftal[64] & 100 & 57 & 37 & 64 & 14409 & 2.1 & 0.64 \\
\hline PA10 & 100 & 30.1 & 21.3 & 73 & 4498 & 1.6 & 0.65 \\
\hline PA15 & 55.5 & 12.1 & 1.3 & 89 & 2498 & 1.0 & 0.63 \\
\hline S10 & 37.5 & 12.7 & 17.6 & 105 & 1860 & 1.7 & 0.66 \\
\hline S15 & 16.6 & 2.4 & 0 & 113 & 540 & 0.9 & 0.55 \\
\hline
\end{tabular}

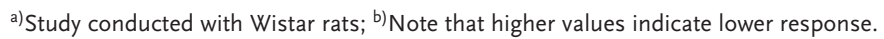

tubes. ${ }^{[8,28]}$ In this study, PA guides allowed for a significantly higher success of regeneration compared to the standard silicone tubes; all the animals regenerated in group PA10, and $55 \%$ in group PA15 (Figure 6I), demonstrating that PA guides are adequate to bridge critical gaps and improve outcome of nerve regeneration. However, for a patient suffering from a peripheral nerve injury, rather than axon or nerve regeneration, functional recovery is the most desirable goal to achieve. In this regard, the PA guides allowed for significant recovery of motor and sensory functions, as shown by quantitative results obtained in motor nerve conduction and sensory von Frey tests, respectively. These results were supported by histological data showing that PA guides had more myelinated axons in comparison with silicone tubes, and allowed for higher motor, sensory, and autonomic reinnervation of the distal targets in the paw, demonstrating that PA guides enhance nerve regeneration in both limiting and critical long gaps. Nevertheless, motor and sensory functional recovery obtained after repair with PA nerve guides do not reach yet the outcomes of $15 \mathrm{~mm}$ rat sciatic nerve defects repaired with autograft (Table 1) obtained previously in our laboratory, ${ }^{[64]}$ despite morphometric analysis shows a similar values between PA and autograft repair, indicating that axonal regeneration should still be further enhanced to reach autograft results. However, it should be taken into account that the length of the gap in the autograft repair does not have the same influence as in regeneration with tube repair. While regeneration is limited in tube repair over critical gaps (e.g., $6 \mathrm{~mm}$ in mice, $15 \mathrm{~mm}$ in rats) when using silicone or other synthetic tubes, ${ }^{[28]}$ similar levels of regeneration take place irrespective of the gap length after autograft repair. ${ }^{[65,66]}$ Thus, the present results are comparable with studies that used other advanced hollow synthetic nerve guides to repair a $15 \mathrm{~mm}$ nerve defect in the rat, such as chitosan, ${ }^{[64]}$ poly-L-lactide-e-caprolactone ${ }^{[67]}$ or poly D,L-lactic acid ${ }^{[68]}$ tubes, that obtained acceptable outcomes of nerve regeneration but still below to autografts. Moreover, it should be considered that PA guides act both as a tube and as a scaffold that is able to bridge long gaps without the need to use an exogenous matrix, providing a promising platform for further development. In fact, a multifactorial approach has been claimed to be necessary to bridge long gaps providing a real alternative to the nerve autograft. ${ }^{[8]}$ The flexibility of the electrospinning technology used to fabricate PA guides makes it possible to not only realize topographical cues but also to improve guide design by incorporating adhesive and encapsulated chemical signals ${ }^{[69,70]}$ as well as living cells, ${ }^{[47]}$ opening an opportunity to take peripheral nerve regeneration a step further.

\section{Conclusion}

PEOT/PBT emerge as a new biomaterial in the field of peripheral nerve regeneration with high perspectives because of their intrinsic properties that include biocompatibility, bioresorption, cell adherence, and cell viability. Our results demonstrate that the PA guide is a promising synthetic conduit to promote nerve regeneration through critical length defects in the injured peripheral nerve.

\section{Experimental Section}

In Vitro Substrate and PEOT/PBT Conduit Preparation: Oriented electrospun PA fibers for in vitro culture were prepared using a custom electrospinning apparatus that maintains humidity at $30 \%$ and temperature at $25^{\circ} \mathrm{C}$ and has a rotating mandrel collector. The PEOT/PBT copolymer 300PEOT55PBT45 (PolyVation B.V., Groningen, Netherlands) was prepared as a $25 \% \mathrm{w} / \mathrm{v}$ solution dissolved overnight in a mixture of chloroform $\left(\mathrm{CHCl}_{3}\right.$, Sigma-Aldrich) and 1,1,1,3,3,3-hexafluoro-2propanol (Biosolve, Netherlands) at a volume ratio of 7:3. The chemical composition of PA is represented by the notation aPEOTbPBTc, where $a$ is the molecular weight, in $\mathrm{g} \mathrm{mol}^{-1}$, of the starting polyethylene glycol (PEG) segments used in the polymerization process, whilst $b$ and $c$ are the weight ratio between PEOT and PBT blocks, respectively. In vitro electrospun substrates were collected on a $60 \mathrm{~mm}$ diameter mandrel rotating at $5000 \mathrm{rpm}$. A $0.8 \mathrm{~mm}$ diameter spinneret was mounted onto a charge parallel plate at a working distance of $13.5 \mathrm{~cm}$ and programmed to translate along the axis of the mandrel $\left(120 \mathrm{~mm} \mathrm{~min}^{-1}\right)$ to ensure even distribution of fiber deposition. A polymer solution flow rate of $1 \mathrm{~mL} \mathrm{~h}^{-1}$ was maintained using a KD Scientific syringe pump. A voltage of $20 \mathrm{kV}$ was applied using a DC high voltage supply (Gamma High Voltage Research, USA). Fibers were deposited onto the mandrel for $10 \mathrm{~min}$. For comparison, substrates of thin PA films were formed with a heated press as previously described, while $2 \mathrm{~mm}$ thick film of poly(dimethylsiloxane) (PDMS, Silgard) was prepared according to suppliers instructions. All samples were prepared as $15 \mathrm{~mm}$ diameter discs. Using the same polymer solution and electrospinning parameters, PA nerve guides were prepared on a $2 \mathrm{~mm}$ diameter, $3 \mathrm{~cm}$ long brass mandrel collector, rotated at a speed of $50 \mathrm{rpm}$. After deposition, the mandrel was placed in $70 \%$ ethanol to ease removal of the nerve guides, and they were left to air dry.

Nerve guides were gold sputter-coated with a Polaron E5600 sputtercoater and examined with an XL 30 ESEM-FEG (Phillips) operating at $10 \mathrm{kV}$ (Figure 1A). The resulting images were used within Image) $(\mathrm{NIH}$, Bethesda, MD) to assess $\approx 100$ fibers, measuring the fiber diameter and fiber orientation angle with respect to the nerve guide longitudinal axis. 
The pore diameters on the inner and outer guide surfaces were similarly evaluated. To analyse the void space, or volume porosity, of the nerve guide wall, samples were placed in liquid nitrogen and cut with a scalpel for a precise "snap freeze" section (Figure 1B). Subsequent SEM images of the cross-section were processed using the default Image) threshold method, producing a binary image (Figure 1C) with the fiber area shown in black and void space shown in white. The ratio of the void space to the overall area was calculated as a measure of porosity. Uniaxial testing was applied to evaluate the mechanical properties of nerve guides and PA thin films for comparison, using a TA Electroforce 3230 with a $100 \mathrm{lbf}$ TA Electroforce load cell and a cross-head speed of $100 \%$ strain $\mathrm{min}^{-1}$ at ambient conditions. The ends of three nerve guides were embedded in TOPFIX 2-part epoxy (Innotec) to facilitate clamping samples. The exposed region between the epoxy-embedded ends was measured $(\approx 5 \mathrm{~mm})$ and the cross-sectional area of the nerve guides was evaluated via SEM. These values were used to calculate the stress/ strain relationship. The mechanical properties of 3 PA thin films were also evaluated. They were prepared using a heated press (Specac) to compress PA pellets to 0.2 tons at $180^{\circ} \mathrm{C}$ for $15 \mathrm{~min}$ within a metal mold, forming $22 \mathrm{~mm}$ discs with a thickness of $0.10 \mathrm{~mm}$; films were cut into dog-bone shapes with a minimal width of $2 \mathrm{~mm}$ and an active length of $7.5 \mathrm{~mm}$. The resulting stress/strain curve was used to determine the Young's modulus, the ultimate strength and the maximum strain before failure.

In Vitro Studies: In vitro assessment of substrate influence on neurites and Schwann cells was performed using oriented PA electrospun fibers, flat PA films and silicone (PDMS) films which were sterilized in $70 \%$ ethanol, washed, and held in a 24 -well plate by Viton o-rings (Eriks). $12 \mathrm{~mm}$ diameter coverslips were also used as control substrates. The $50 \mathrm{~B} 11$ neural cell line (a kind gift from Dr. Höke ${ }^{[71]}$ ) was seeded at a density of 10000 cells $\mathrm{cm}^{-2}$ and maintained for $16 \mathrm{~h}$ (overnight) in neural basal medium (Invitrogen) with N21-MAX supplement (R\&D Systems), $0.2 \times 10^{-3} \mathrm{M}$ glutamine, penicillin/streptomycin, and $10 \%$ fetal bovine serum (FBS, Sigma-Aldrich). Cultures were then washed with phosphate buffered saline (PBS) and medium was replaced by neural basal medium (Invitrogen) with N21-MAX supplement (R\&D Systems), $0.2 \times 10^{-3} \mathrm{M}$ GlutaMAX (Invitrogen), penicillin/streptomycin, $50 \mathrm{ng} \mathrm{mL} \mathrm{m}^{-1}$ of recombinant human NGF- $\beta$ (Sigma-Aldrich), and $25 \mu \mathrm{m}$ of Forskolin (Sigma-Aldrich). Cultures were maintained for $32 \mathrm{~h}$. Separate substrates were seeded with the Schwann cell line RT4-D6P2T (ATCC, USA) at 20000 cells $\mathrm{cm}^{-2}$, maintained in Dulbecco's Modified Eagle Medium (DMEM) high glucose medium supplemented with $2 \times 10^{-3} \mathrm{M}$ GlutaMAX (Invitrogen), penicillin/streptomycin, and $10 \%$ FBS and cells were maintained for $48 \mathrm{~h}$. Cultures were fixed in $4 \%$ paraformaldehyde for $20 \mathrm{~min}$ at $4{ }^{\circ} \mathrm{C}$, followed by permeabilization with $0.1 \%$ TritonX (Sigma-Aldrich) for $15 \mathrm{~min}$ at room temperature, and a blocking solution of $5 \%$ goat serum for $1 \mathrm{~h}$ at room temperature. After $12 \mathrm{~h}$ incubation at $4{ }^{\circ} \mathrm{C}$ with primary antibodies mouse anti- $\beta \| \mathrm{II}$-tubulin antibody (1:1000; Sigma-Aldrich) and rabbit anti-S100 antibody (1:500; Sigma-Aldrich) for neural and Schwann cell cultures, respectively, samples were incubated at room temperature for $1 \mathrm{~h}$ with anti-mouse Alexa 488 antibody and anti-rabbit Alexa 568 antibody produced in goat (Invitrogen). Samples were imaged with a Nikon TI-E epifluorescent microscope.

To confirm the primary cell response, PA conduits were longitudinally cut, opened to create flat sheets and held in a 24 well plate using Viton o-rings (Eriks) with the internal surface of the guide facing up. DRG were excised from $2 \mathrm{~d}$ old Wistar rat pups; following a procedure approved by the Utrecht Animal Use Committee (DEC) according to Dutch law (as stated in the "Wet op de dierproeven"). DRG were cut in half and placed on the nerve guide and maintained in neural basal medium (Invitrogen) with B27 supplement, $0.2 \times 10^{-3} \mathrm{M}$ glutamine, penicillin/streptomycin, and $50 \mathrm{ng} \mathrm{mL}^{-1}$ of recombinant human NGF- $\beta$ (Sigma-Aldrich). As a control, DRG were also seeded on glass coverslips (VWR) previously coated with $20 \mu \mathrm{g} \mathrm{mL} \mathrm{m}^{-1}$ of poly-D-lysine (Sigma-Aldrich) and $10 \mu \mathrm{g} \mathrm{mL} \mathrm{L}^{-1}$ of laminin (Sigma-Aldrich). ${ }^{[72]}$ Medium was refreshed every 2 to $3 \mathrm{~d}$ and cultures were maintained for $5 \mathrm{~d}$. Immunofluorescence for both neurites and Schwann cells was applied as described above. Imaging was performed with either a
Nikon Al confocal or a BD Pathway 435 Imager, with the resulting collection of overlapping images finally stitched to form a large image using the Image) Grid Stitching Plug-in. ${ }^{[73]}$ To evaluate pattern of neurite outgrowth and Schwann cell migration analysis, a polar histogram was created that represents the associated distribution of fluorescence intensity centered around the DRG (i.e., the DRG was excluded). The average intensity of neurites and Schwann cells immunofluorescence was measured per histogram bin with an angular "width" of $2^{\circ}$ and a fixed area of 500 and $50 \mu \mathrm{m}$ per bin, respectively (Figure $2 \mathrm{C}$ ). To determine the orientation of neurite growth and Schwann cell migration on nerve guides, the intensity of immunofluorescence was evaluated to produce a "center of mass" of the neurite and Schwann cell growth per radius. Calculating this point for every radius resulted in a line emanating from the DRG, with the orientation calculated as the average angle of this resulting line. This orientation was compared to the visually assessed orientation of the underlying nerve guide fibers. To measure the cohesion of oriented neurite growth and Schwann cell migration, the width of the dispersion of immunofluorescence from this calculated orientation line was evaluated. The dispersion was calculated for every radius, normalized between 0 (no dispersion) and 1 (maximal $90^{\circ}$ deviation), and averaged along the calculated orientation line to describe the pattern of growth.

In Vivo Studies: Adult female Sprague Dawley rats (250-300 g) were used in this study. All animals were kept on standard laboratory conditions with a light-dark cycle of 12:12 $\mathrm{h}$ and ad libitum access to food and tap water. The experimental procedures were approved by the ethical committee of the Universitat Autonoma de Barcelona in accordance with the European Directive 2010/63/EU on the use of animals for scientific purposes. All efforts were made to minimize pain and animal discomfort during surgery and treatments.

Animals were anesthetized with an intraperitoneal injection of sodium pentobarbital $\left(40 \mathrm{mg} \mathrm{kg}^{-1}\right)$, the right sciatic nerve was then exposed at the midthigh and sectioned $92 \mathrm{~mm}$ from the tip of the third toe, and a distal nerve segment resected. Before implantation, nerves guides were sterilized in $70 \%$ ethanol and washed in sterile water. In order to assess whether PEOT/PBT could be a good material to sustain peripheral nerve regeneration, a short-term study (15 and $30 \mathrm{~d}$ after repair) was conducted with silicone or PA nerve guides that were sutured with 10-0 monofilament sutures (Alcon) to the nerve stumps leaving a $6 \mathrm{~mm}$ gap between both nerve ends ( $n=4$ per group). Once the proof-of-concept was set, a long-term reinnervation study $(120 \mathrm{~d}$ after repair) was conducted in different groups of rats with the aim to repair either a limiting gap of $10 \mathrm{~mm}$ with silicone $(\mathrm{S} 10, n=8)$ or PA (PA10, $n=9$ ) guides or a longer $15 \mathrm{~mm}$ critical gap with silicone $(\mathrm{S} 15, n=6)$ or PA (PA15, $n=9$ ) guides (see Figure 3A,C). After implanting the tubes, the wound was closed by planes with silk sutures and animals were left to recover from the anesthesia on a warming pad before being housed again.

Morphological Evaluation of Nerve Regeneration: After 15, 30, or 120 dpo animals were deeply anesthetized and perfused with $4 \%$ paraformaldehyde in PBS. Before nerve processing, silicone tubes were carefully removed and only the regenerated cable was processed, whereas in PA groups the regenerated nerve and tube were processed together because the strong adherence between them. The regenerated sciatic nerves were divided in two halves, proximal sections were postfixed in the same perfusion solution for $4 \mathrm{~h}$ and then cryoprotected in PBS-sucrose $30 \%$ with azide $0.1 \%$ at $4{ }^{\circ} \mathrm{C}$ before cryosectioning. The distal parts were postfixed with $3 \%$ glutaraldehyde- $3 \%$ paraformaldehyde in cacodylate-buffer solution $(0.1 \mathrm{M}, \mathrm{pH} 7.4)$ before their processing for morphological evaluation.

For immunostaining, the regenerated nerves were serially cut into $15 \mu \mathrm{m}$ thick sections on a cryostat (Leica Microsystems, Germany) and collected on gelatin-coated slides. The sections were blocked and permeabilized with $0.3 \%$ Triton-X100 and $5 \%$ normal donkey or goat serum for $30 \mathrm{~min}$. Then, slides were incubated with rabbit anti$\beta$ III-tubulin (1:500, Covance) to stain all axons and rabbit anti-S100 (1:200, Immunostar) to stain Schwann cells overnight at $4{ }^{\circ} \mathrm{C}$ in $0.1 \%$ Triton-PBS. After washes in PBS, slides were incubated with Alexa 488 or Alexa 594-conjugated secondary antibodies (1:200; Life Sciences) for $1 \mathrm{~h}$. For S100 biotin amplification, samples were incubated with 
biotinylated anti-rabbit antibody (1:200, Vector) and, after washes, with Alexa Fluor 488 streptavidin (1:200; Life Sciences). The sections were coverslipped with Mowiol mounting medium containing 4'-6-Diamidino-

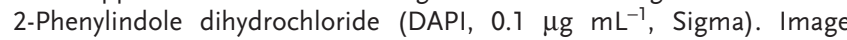
acquisition was performed with an epifluorescence microscope BX51 (Olympus) and a DP73 digital camera (Olympus).

For light microscopy analysis, nerves were postfixed in $\mathrm{OsO}_{4}(2 \%, 2 \mathrm{~h})$ and dehydrated through ethanol series prior to embedding in Epon resin. Semithin sections ( $0.5 \mu \mathrm{m}$ thick) taken at the mid tube level were stained with toluidine blue and examined by light microscopy. Images of the whole sciatic nerve were acquired with an Olympus DP50 camera attached to computer. Sets of images for analysis obtained at $100 \times$ were chosen by systematic sampling of squares representing at least $30 \%$ of the nerve cross-sectional area. Measurements of cross-sectional area of the whole nerve and counts of the number of myelinated nerve fibers were carried out using Image). ${ }^{[74]}$ Axon diameter and myelin thickness were determined on images of systematic randomly selected fields covering at least 300 myelinated fibers per animal with the help of a computer-linked digitizing tablet and a specific BASIC software for morphometric analysis ${ }^{[75]}$. Animals with no nerve regeneration received zero values for endoneurial area and number of myelinated fibers, but morphometric analysis included only animals with regenerated fibers at the mid-tube level.

Evaluation of Distal Target Reinnervation and Functional Recovery: In the long-term study, noninvasive nerve conduction tests of the sciatic nerve were performed at 60,90 , and $120 \mathrm{dpo}$ to record CMAP of different muscles and thus assess functional reinnervation and motor recovery. Briefly, animals were anesthetized, placed on a warm plate and the sciatic nerve was stimulated percutaneously through a pair of monopolar needle electrodes at the sciatic notch with single electrical pulses at supramaximal intensity. The CMAP from the TA, GM, and PL muscles were recorded with small needle electrodes placed into the muscle belly. ${ }^{[67]}$ The tests were performed using an electromyograph (Sapphire 4M, Medelec Vickers). Control values for each rat were obtained from the intact left hind limb.

Sensory functional recovery was assessed by the response to nonnoxious mechanical stimuli applied by an electronic Von Frey algesimeter (Bioseb, Chaville, France) at 7, 60, 90, and 120 dpo. ${ }^{[76]}$ Rats were placed on a wire net platform in plastic chambers 30 min before the experiment for habituation. Then, the lateral area of the operated paw, normally innervated by the sciatic nerve, was tested and the contralateral paw was used as control. The mechanical threshold was taken as the mean of three measurements per paw, expressed as the force (in grams) at which rats withdrew their paws in response to the stimulus. A cutoff force was set to $40 \mathrm{~g}$, at which stimulus lifted the paw with no response.

At the end of follow-up, footpads, representing a cutaneous target of the sciatic nerve, were harvested and processed as indicated above (5.4), but with primary antibody against PGP 9.5 (1:500, ABD Serotec) a cytoplasmic peptide selectively found in all neurons to stain axons innervating the skin. ${ }^{[77]}$ For analysis, images of three sections of each sample were collected with an Olympus DP50 digital camera to count the number of IENF per skin $\mathrm{mm}$ and the number of reinnervated SGs in the pad.

Data Analysis: Data are presented as mean \pm SEM unless otherwise stated. Analysis of statistical significance was performed using GraphPad Prism (GraphPad Software version 6.0, USA) software. Student's t-test, two-way ANOVA followed by Bonferroni's post hoc test or chi-square test for comparisons between groups were used when appropriate. Statistical significance was considered when $P$ value was $<0.05$.

\section{Supporting Information}

Supporting Information is available from the Wiley Online Library or from the author.

\section{Acknowledgements}

D.S. and P.W. contributed equally to this work. This research was supported by the European Union FP7-NMP project MERIDIAN under contract number 280778 and FPT-ICT project NEBIAS under contract number 611687, TERCEL and CIBERNED funds from the Instituto de Salud Carlos III of Spain, FEDER funds, and the Natural Science and Engineering Research Council of Canada (NSERC). This research was also made possible with the support of the Dutch Province of Limburg. The authors acknowledge the support of Prof. Silvestro Micera, from Scuola Superiore Sant'Anna, Pisa, throughout this study and thank the technical help of Monica Espejo, Jessica Jaramillo, and Marta Morell.

Received: March 21, 2016

Revised: November 7, 2016

Published online: December 14, 2016

[1] G. A. Georgeu, E. T. Walbeehm, R. Tillett, A. Afoke, R. A. Brown, J. B. Phillips, Cell Tissue Res. 2005, 320, 229.

[2] S. Hall, J. Bone Joint Surg. Br. 2005, 87, 1309.

[3] R. Robinson, Muscle Nerve 2000, 23, 863.

[4] W. Daly, L. Yao, D. Zeugolis, A. Windebank, A. Pandit, J. R. Soc. Interface 2012, 9, 202.

[5] E. O. Johnson, P. N. Soucacos, Injury 2008, 39, S30.

[6] M. E. H. Boeckstyns, A. I. Sørensen, J. F. Viñeta, B. Rosén, X. Navarro, S. J. Archibald, J. Valss-Solé, M. Moldovan, C. Krarup, J. Hand Surg. Am. 2013, 38, 2405.

[7] S. Kehoe, X. F. Zhang, D. Boyd, Injury 2012, 43, 553.

[8] R. Deumens, A. Bozkurt, M. F. Meek, M. A. E. Marcus, E. A. J. Joosten, J. Weis, G. A. Brook, Prog. Neurobiol. 2010, 92, 245.

[9] M. Butí, E. Verdú, R. O. Labrador, J. J. Vilches, J. Forés, X. Navarro, Exp. Neurol. 1996, 137, 26

[10] G. Lundborg, L. B. Dahlin, N. Danielsen, R. H. Gelberman, F. M. Longo, H. C. Powell, S. Varon, Exp. Neurol. 1982, 76, 361.

[11] L. R. Williams, F. M. Longo, H. C. Powell, G. Lundborg, S. Varon, J. Comp. Neurol. 1983, 218, 460.

[12] S. J. Archibald, J. Shefner, C. Krarup, R. D. Madison, J. Neurosci. $1995,15,4109$

[13] W. T. Daly, A. M. Knight, H. Wang, R. de Boer, G. Giusti, M. Dadsetan, R. J. Spinner, M. J. Yaszemski, A. J. Windebank, Biomaterials 2013, 34, 8630.

[14] A. C. Pinho, A. C. Fonseca, A. C. Serra, J. D. Santos, J. F. J. Coelho, Adv. Healthcare Mater. 2016, 5, 2732.

[15] D. Arslantunali, T. Dursun, D. Yucel, N. Hasirci, V. Hasirci, Med. Dev. Evid. Res. 2014, 7, 405.

[16] G. C. W. de Ruiter, M. J. A. Malessy, M. J. Yaszemski, A. J. Windebank, R. J. Spinner, Neurosurg. Focus 2009, 26, E5.

[17] E. T. Pashuck, M. M. Stevens, Sci. Transl. Med. 2012, 4, 160sr4.

[18] M. A. Serban, Curr. Opin. Biotechnol. 2016, 40, 31.

[19] X. Gu, F. Ding, D. F. Williams, Biomaterials 2014, 35, 6143.

[20] E. J. P. Jansen, J. Pieper, M. J. J. Gijbels, N. A. Guldemond, J. Riesle, L. W. van Rhijn, S. K. Bulstra, R. Kuijer, J. Biomed. Mater. Res. - Part A 2009, 89, 444.

[21] S. Danti, C. Mota, D. D'alessandro, L. Trombi, C. Ricci, S. L. Redmond, A. De Vito, R. Pini, R. J. Dilley, L. Moroni, S. Berrettini, Hear. Balanc. Commun. 2015, 13, 133.

[22] L. Moroni, R. Schotel, D. Hamann, J. R. de Wijn, C. A. van Blitterswijk, Adv. Funct. Mater. 2008, 18, 53.

[23] G. J. Meijer, A. Radder, R. Dalmeijer, C. de Putter, C. A. van Blitterswijk, J. Oral Rehabil. 1995, 22, 167.

[24] S. K. Bulstra, R. G. Geesink, D. Bakker, T. H. Bulstra, S. J. Bouwmeester, A. J. van der Linden, J. Bone Joint Surg. Br. 1996, 78,892

[25] D. Henley, Food Drug Adm. Drug Eval. Res. 2002, K023680.

[26] W. Liu, S. Thomopoulos, Y. Xia, Adv. Healthcare Mater. 2012, 1, 10.

[27] V. Milleret, B. Simona, P. Neuenschwander, H. Hall, Eur. Cells Mater. 2011, 21, 286

[28] I. V. Yannas, B. J. Hill, Biomaterials 2004, 25, 1593. 
[29] F. F. A. IJpma, R. C. van De Graaf, M. F. Meek, J. Hand Surg. Eur. Vol. 2008, 33, 581.

[30] F. González-Pérez, E. Udina, X. Navarro, Int. Rev. Neurobiol. 2013, 108, 257.

[31] I. Allodi, E. Udina, X. Navarro, Prog. Neurobiol. 2012, 98, 16.

[32] Y. Gu, J. Zhu, C. Xue, Z. Li, F. Ding, Y. Yang, X. Gu, Biomaterials 2014, 35, 2253.

[33] S. Madduri, B. Gander, J. Controlled Release 2012, 161, 274.

[34] P. Ramburrun, P. Kumar, Y. E. Choonara, D. Bijukumar, L. C. Du Toit, V. Pillay, Biomed. Res. Int. 2014, 2014, 13.

[35] T. M. Dinis, R. Elia, G. Vidal, Q. Dermigny, C. Denoeud, D. L. Kaplan, C. Egles, F. Marin, J. Mech. Behav. Biomed. Mater. 2015, 41, 43.

[36] S. Das, M. Sharma, D. Saharia, K. K. Sarma, M. G. Sarma, B. B. Borthakur, U. Bora, Biomaterials 2015, 62, 66.

[37] S. Madduri, M. Papaloïzos, B. Gander, Biomaterials 2010, 31, 2323.

[38] K. Haastert-Talini, S. Geuna, L. B. Dahlin, C. Meyer, L. Stenberg, T. Freier, C. Heimann, C. Barwig, L. F. V Pinto, S. Raimondo, G. Gambarotta, S. R. Samy, N. Sousa, A. J. Salgado, A. Ratzka, S. Wrobel, C. Grothe, Biomaterials 2013, 34, 9886.

[39] R. Singh, K. Mechelse, W. C. J. Hop, R. Braakman, Surg. Neurol. 1992, 37, 425

[40] S. Panseri, C. Cunha, J. Lowery, U. Del Carro, F. Taraballi, S. Amadio, A. Vescovi, F. Gelain, BMC Biotechnol. 2008, 8, 39.

[41] W. Yu, W. Zhao, C. Zhu, X. Zhang, D. Ye, W. Zhang, Y. Zhou, X. Jiang, Z. Zhang, BMC Neurosci. 2011, 12, 68.

[42] S. Y. Chew, R. Mi, A. Hoke, K. W. Leong, Adv. Funct. Mater. 2007, 17, 1288.

[43] H. S. Koh, T. Yong, W. E. Teo, C. K. Chan, M. E. Puhaindran, T. C. Tan, A. Lim, B. H. Lim, S. Ramakrishna, J. Neural Eng. 2010, 7, 1.

[44] J. H. A. Bell, J. W. Haycock, Tissue Eng. Part B 2012, 18, 116.

[45] A. Townsend-Nicholson, S. N. Jayasinghe, Biomacromolecules 2006, 7, 3364.

[46] J. J. Stankus, J. Guan, K. Fujimoto, W. R. Wagner, Biomaterials 2006, 27, 735 .

[47] S. N. Jayasinghe, Analyst 2013, 138, 2215.

[48] A. Subramanian, U. M. Krishnan, S. Sethuraman, Biomed. Mater. 2011, 6, 25004

[49] E. Schnell, K. Klinkhammer, S. Balzer, G. Brook, D. Klee, P. Dalton, J. Mey, Biomaterials 2007, 28, 3012.

[50] Y. Panahi-Joo, A. Karkhaneh, A. Nourinia, B. Abd-Emami, B. Negahdari, P. Renaud, S. Bonakdar, Biomed. Mater. 2016, 11, 25017.

[51] B. S. Jha, R. J. Colello, J. R. Bowman, S. A. Sell, K. D. Lee, J. W. Bigbee, G. L. Bowlin, W. N. Chow, B. E. Mathern, D. G. Simpson, Acta Biomater. 2011, 7, 203.

[52] Y. Zhu, A. Wang, S. Patel, K. Kurpinski, E. Diao, X. Bao, G. Kwong, W. L. Young, S. Li, Tissue Eng. Part C Methods 2011, 17, 705.

[53] H. B. Wang, M. E. Mullins, J. M. Cregg, C. W. McCarthy, R. J. Gilbert, Acta Biomater. 2010, 6, 2970.
[54] M. Buitinga, R. Truckenmüller, M. A. Engelse, L. Moroni, H. W. M. Ten Hoopen, C. A. van Blitterswijk, E. J. P. de Koning, A. A. van Apeldoorn, M. Karperien, PLoS One 2013, 8, e64772.

[55] Y. Li, G. A. Thouas, Q. Chen, J. Mech. Behav. Biomed. Mater. 2014, 40, 210.

[56] M. F. Meeks, W. F. A. den Dunnen, Microsurgery 2009, 29 , 473.

[57] A. A. Deschamps, M. B. Claase, W. J. Sleijster, J. D. De Bruijn, D. W. Grijpma, J. Feijen, J. Controlled Release 2002, 78, 175.

[58] I. P. Clements, Y. Kim, A. W. English, X. Lu, A. Chung, R. Bellamkonda, Biomaterials 2009, 30, 3834.

[59] W. Huang, R. Begum, T. Barber, V. Ibba, N. C. H. Tee, M. Hussain, M. Arastoo, Q. Yang, L. G. Robson, S. Lesage, T. Gheysens, N. J. V Skaer, D. P. Knight, J. V. Priestley, Biomaterials 2012, 33, 59

[60] T. T. B. Ngo, P. J. Waggoner, A. A. Romero, K. D. Nelson, R. C. Eberhart, G. M. Smith, J. Neurosci. Res. 2003, 72, 227.

[61] M. Merle, A. L. Dellon, J. N. Campbell, P. S. Chang, Microsurgery $1989,10,130$

[62] S. H. Oh, J. H. Kim, K. S. Song, B. H. Jeon, J. H. Yoon, T. B. Seo, U. Namgung, I. W. Lee, J. H. Lee, Biomaterials 2008, 29, 1601.

[63] F. J. Rodriguez, N. Gomez, G. Perego, X. Navarro, Biomaterials 1999, 20, 1489.

[64] F. González-Pérez, S. Cobianchi, S. Geuna, C. Barwig, T. Freier, E. Udina, X. Navarro, Microsurgery 2015, 35, 300.

[65] N. Gómez, J. Cuadras, M. Butí, X. Navarro, Restor. Neurol. Neurosci. 1996, 10, 187

[66] F. J. Rodríguez, N. Gómez, R. O. Labrador, M. Butí, D. Ceballos, J. Cuadras, E. Verdú, X. Navarro, Restor. Neurol. Neurosci. 1999, 14, 65.

[67] A. Valero-Cabré, K. Tsironis, E. Skouras, G. Perego, X. Navarro, W. F. Neiss, J. Neurosci. Res. 2001, 223, 214.

[68] H.-C. Ni, T.-C. Tseng, J.-R. Chen, S.-H. Hsu, I.-M. Chiu, Biofabrication 2013, 5, 35010

[69] T. J. Whitehead, H. G. Sundararaghavan, J. Visualized Exp. 2014, 1, e51517.

[70] D. Santos, G. Giudetti, S. Micera, X. Navarro, J. del Valle, Brain Res. 2016, 1636, 93

[71] W. Chen, R. Mi, N. Haughey, M. Oz, A. Höke, J. Peripher. Nerv. Syst. 2007, 12, 121.

[72] S. A. Malin, B. M. Davis, D. C. Molliver, Nat. Protoc. 2007, 2, 152.

[73] S. Preibisch, S. Saalfeld, P. Tomancak, Bioinformatics 2009, 25, 1463.

[74] C. A. Schneider, W. S. Rasband, K. W. Eliceiri, Nat. Methods 2012, 9, 671.

[75] E. Fernández, N. Cuenca, J. De Juan, J. Neurosci. Methods 1991, 39 , 271.

[76] S. Cobianchi, J. de Cruz, X. Navarro, Exp. Neurol. 2014, 255, 1.

[77] X. Navarro, E. Verdu, G. Wendelschafer-Crabb, W. R. Kennedy, J. Neurosci. Res. 1995, 41, 111. 